\title{
Cambios clínicos, hemáticos y coagulativos consecuentes al aumento de anticuerpos en equinos productores de suero antiofídico
}

\author{
Bogado, F.'; Núñez, S. ${ }^{2}$; Mussart, N.B. ${ }^{3}$; Leiva, L. ${ }^{4}$; Acosta, O.C. ${ }^{1}$ \\ ${ }^{1}$ Departamento Clínicas, ${ }^{2}$ Cátedra de Inmunología, ${ }^{3}$ Cátedra de Fisiología, Facultad de Ciencias Veterinarias, \\ UNNE, Sargento Cabral 2139, Corrientes (3400), Argentina. ${ }^{4}$ Cátedra de \\ Química Biológica I, Facultad Ciencias Exactas, UNNE. \\ E-mail: patmed@vet.unne.edu.ar.
}

\begin{abstract}
Resumen
Bogado, F.; Núñez, S.; Mussart, N.B.; Leiva, L.; Acosta, O.C.: Cambios clínicos, hemáticos y coagulativos consecuentes al aumento de anticuerpos en equinos productores de suero antiofídico. Rev. vet. 24: 1, 3-9, 2013. El objetivo del trabajo consistió en estudiar los efectos clínicos, hemáticos y coagulativos, así como la producción de anticuerpos en tres equinos inmunizados para la producción de suero antiofídico monovalente contra Bothrops alternatus y evaluar los resultados obtenidos correlacionando la respuesta inmune humoral con el estado de salud de los animales. Los resultados indicaron que la inmunización de los equinos con el protocolo utilizado, indujo alteraciones clínicas menores y cambios en ciertos parámetros del hemograma y pruebas coagulativas. Se registraron variaciones de la capacidad neutralizante sobre distintos componentes del veneno, en especial las toxinas que afectan la coagulación de la sangre. Asimismo, se constató una correlación directa entre las tasas séricas de leucocitos y la producción de inmunoglobulinas. Los resultados indicaron que el período de descanso de un trimestre resulta extenso y causa una franca disminución del título de anticuerpos, perdiendo el suero capacidad neutralizante de la toxicidad del veneno; no obstante, al reanudar las inoculaciones los equinos presentaron una rápida reposición de los anticuerpos anti-toxinas de $B$. alternatus, tolerando altas dosis de veneno en el segundo período de inmunización.
\end{abstract}

Palabras clave: equino, inmunización, Bothrops alternatus, hemograma, coagulación.

\begin{abstract}
Bogado, F.; Núñez, S.; Mussart, N.B.; Leiva, L., Pérez, O.A.: Clinical, hematological and coagulative changes consequent to antibody level increase in horses destined to antivenom production. Rev. vet. 24: 1, 3-9, 2013. The aim of this work consisted to study the clinical and hematological effects that included blood coagulation and antibody production of a group of three horses immunized for the production of monovalent serum against Bothrops alternatus venom, in order to correlate the results with the humoral immune response of the animals. The results showed that immunization of horses with the essayed protocol induce slight clinic alterations and discrete changes in some parameters of the hemogram. Results also showed variations in the neutralizing capacity of the serum on different venom components, particularly toxins that affect blood coagulation. Also, it was verified a direct relationship between the rate of white blood cells and serum immunoglobulin production. Furthermore, they also indicate that the three-month rest period may be considered as too long as it causes a marked decrease in antibody titles, losing the serum its neutralizing capacity to venom compounds. Nevertheless, after re-administration of venom horses provided a rapid reposition of anti-toxins against B. alternatus venom, tolerating high venom doses during this second period of immunization.
\end{abstract}

Key words: horse, immunization, Bothrops alternatus, hemogram, coagulation.

\section{INTRODUCCIÓN}

El litoral argentino es habitado por varias especies de serpientes de la familia Viperidae, entre ellas Bothrops alternatus (yarará grande, víbora de la cruz),

Recibido: 27 diciembre 2012 / Aceptado: 7 mayo 2013 Proyecto PFIP/2005 - COFECyT responsable de la mayoría de los accidentes que ocurren en dicha región cuando la serpiente muerde descargando su secreción salival (veneno) en la víctima ${ }^{14}$. El tratamiento de la intoxicación ofídica consiste en la administración de inmunoglobulinas, anticuerpos que neutralizan las toxinas del veneno. Tales anticuerpos se obtienen del suero de equinos previamente inmu- 
nizados, por ello se lo conoce como suero antiofídico hiperinmune equino ${ }^{10}$.

Para estimular la producción de estos anticuerpos los caballos son sometidos a dosis sub-letales progresivas de veneno, las cuales no causan la muerte del animal sino que estimulan al sistema inmune para producir inmunoglobulinas contra las distintas proteínas inoculadas. La administración del antiveneno específico para el tratamiento de las mordeduras por ofidios ponzoñosos es una práctica mundialmente aceptada $8,9,12$.

Los antígenos que reciben los equinos en el proceso de inmunización les generan cambios fisiopatológicos no bien evaluados hasta la fecha. Estudios realizados por otros investigadores han demostrado alteraciones en el medio interno, evidenciadas a través de pruebas hematológicas y bioquímicas ${ }^{1}$. Es importante identificar tales anomalías sistémicas porque la composición de los venenos varía con la región geográfica que habitan las serpientes ${ }^{3}$, de allí la sugerencia de la OMS en el sentido que los sueros sean producidos por inmunización de mamíferos a partir del veneno de serpientes de la región en que serán utilizados los sueros hiperinmunes obtenidos ${ }^{8,10}$.

El propósito del trabajo fue estudiar los efectos de la inmunización con veneno de $B$. alternatus sobre algunos parámetros semiológicos, sanguíneos y hemostáticos del caballo, y correlacionarlos con la magnitud de la respuesta inmune humoral (producción de anticuerpos).

\section{MATERIAL Y MÉTODOS}

Animales. Se utilizaron tres equinos adultos de 3 a 4 años de edad, con pesos de 450 a $550 \mathrm{~kg}$. Previamente a la inmunización los animales fueron desparasitados y sometidos a controles semiológicos y de laboratorio, incluyendo el test de Coggins (Immunology Lab.) para descartar la presencia de anemia infecciosa equina. Luego de cada vacunación los animales fueron nuevamente objeto de controles clínicos y extracciones de sangre para distintos estudios.

Preparación de la vacuna. El veneno de B. alternatus fue obtenido de ejemplares adultos del serpentario del Zoológico de la Ciudad de Corrientes (Argentina). Luego de la extracción, el pool de veneno fue centrifugado para descartar residuos y desecado, manteniéndose a $-20^{\circ} \mathrm{C}$ hasta el momento de su uso. Para la inmunización, se disolvió en buffer fosfato (PBS, pH 7,2) y se filtró a través de una membrana de nitrocelulosa de $0,22 \mu \mathrm{m}$ (Millipore). Finalmente fue mezclado con adyuvante de Freund completo en la primera vacunación y adyuvante de Freund incompleto en las restantes.

Protocolo de inmunización. El volumen inoculado en cada animal fue de $10 \mathrm{ml}$, los que se aplicaron por vía $\mathrm{SC}$ en dosis de $2 \mathrm{ml}$ en 5 puntos diferentes de la tabla del cuello, acorde al siguiente detalle: dosis inicial de $0,75 \mathrm{mg}$ más adyuvante de Freund completo, continuándose con dosis sucesivas crecientes a intervalos de 21 días a razón de 1,$5 ; 5,0 ; 5,5 ; 10 ; 15 ; 22 ; 30 ; 45$ y $45 \mathrm{mg}$ (dosis expresadas en mg de veneno), en estos casos con adyuvante de Freund incompleto. Luego de un período de descanso de 3 meses se realizó la revacunación con dosis de 15 y $30 \mathrm{mg}$ de veneno con adyuvante Freund incompleto para medir la respuesta inmunológica.

Estudio clínico. Inicialmente y durante el proceso de inmunización se controló el estado clínico de cada equino, incluyendo la exploración del área de vacunación, auscultación de los sistemas cardíaco, respiratorio y digestivo, así como examen de mucosas y conjuntivas aparentes.

Hemograma. Previamente al inicio de las vacunaciones y 24 horas después de cada una de ellas, se tomaron muestras de sangre de los equinos con anticoagulante EDTA (1 gota cada $5 \mathrm{ml}$ de sangre), para obtener los valores del hemograma. Tal estudio comprendió las determinaciones de hematocrito (capilares centrifugados a $12.000 \mathrm{rpm}$ ), hemoglobina (método fotocolorimétrico de Drabkin, lecturas a $540 \mathrm{~nm}$ ), recuento de leucocitos (en analizador electrónico Sequoia-Turner 500) y fórmula leucocitaria (recuento microscópico diferencial de 200 células a partir de frotis coloreados con Giemsa, reactivos Biopur).

Cuantificación de anticuerpos. Para la determinación de los títulos de anticuerpos, las muestras sanguíneas fueron obtenidas previamente a cada administración del inóculo (sin anticoagulante) cada 21 días. La valoración sérica se realizó mediante enzimoinmunoensayo (ELISA). Para ello, en policubetas de 9x12 fosas se fijaron moléculas de antígeno (veneno) por interacciones hidrofóbicas a las paredes de las cubetas, colocándose $100 \mu \mathrm{l}$ de una solución antigénica de $10 \mu \mathrm{g} / \mathrm{ml}$ y se incubó $1 \mathrm{~h}$ a $37 \mathrm{C}^{\circ}$. Luego se efectuaron diluciones seriadas de los sueros equinos. El revelado se realizó por el agregado de una anti-gammaglobulina de equino conjugada a una peroxidasa (Anti-Horse Immunoglobulin Conjugate-AIgG, Sigma 6154) en una dilución de 1/10.000. Como sustrato de la enzima se utilizó una solución de orto fenilendiamina ( $1 \mathrm{mg} / \mathrm{ml}$ en buffer sustrato). La reacción se detuvo con el agregado de una solución de $\mathrm{H}_{2} \mathrm{SO}_{4} 3 \mathrm{~N}$ luego del desarrollo de color. La densidad óptica se midió en un lector de microplaca a $492 \mathrm{~nm}^{16}$.

Pruebas de coagulación. Empleando plasma citratado obtenido de equinos en estado basal, a las 1, 3, 6 y 24 h posteriores a la inyección de cada dosis de veneno, se realizaron pruebas de laboratorio para determinar el tiempo de protrombina (método de Quick), recalcificación plasmática (Howell) y fibrinógeno (von Clauss). Finalizado el protocolo se evaluó la capacidad neutralizante del suero del equino inmunizado sobre la actividad coagulante del veneno botrópico.

Pruebas de neutralización. Las muestras ensayadas consistieron en mezclas de veneno $(4 \mathrm{mg} / \mathrm{ml})$ preincubadas con igual volumen de suero equino hiperinmune de cada instancia del sangrado. El veneno entero preincubado con PBS fue utilizado como control de referencia (máxima actividad) para calcular el porcentaje de neutralización de cada actividad.

Neutralización de la actividad hemolítica. La neutralización de la actividad hemolítica se evaluó a través 
de hemólisis radial indirecta. Las muestras se sembraron en placas de agar-sangre enriquecidas con lecitina de huevo, los halos de hemólisis fueron valorados luego de $20 \mathrm{~h}$ de incubación a $37^{\circ} \mathrm{C}^{5}$. Como control positivo de la actividad se sembró una mezcla en la cual se omitió el suero equino reemplazándolo por igual volumen de PBS.

Neutralización de la actividad proteolítica. Para evaluar la capacidad neutralizante de la actividad proteolítica se empleó como sustrato azocaseína ${ }^{18}$. En un espectrofotómetro se midió la absorbancia a $450 \mathrm{~nm}$, utilizándose un blanco de reacción en el cual se omitió la fracción de veneno, reemplazada por igual volumen de PBS. Como control positivo de la actividad se omitió el suero equino reemplazándolo por igual volumen de PBS.

Neutralización de la actividad coagulante. La actividad coagulante se midió en coagulómetro (Fibrintimer Wiener Lab.) con suero hiperinmune pre-incubado con veneno entero, posteriormente adicionado con igual volumen de plasma humano citratado. Se tomó como control positivo la misma dosis de reto de veneno incubada con PBS ${ }^{17}$.

Estadísticas. Los cálculos estadísticos fueron enmarcados en un diseño completamente aleatorizado, con arreglo factorial 4 por 7 (4 tiempos de control postinoculación 7 dosis diferentes de veneno). Se efectuó estadística descriptiva (media aritmética, desvío estándar), a los fines de estimar el comportamiento de los datos. Posteriormente los resultados fueron sometidos a comprobación de los supuestos de normalidad (WilkShapiro) y homocedasticidad de las variancias (Levene) y por las características del diseño se cumplió con el supuesto de independencia. El grado de asociación lineal entre variables se evaluó mediante el coeficiente de correlación de Pearson. Por último se procedió a realizar el análisis de la varianza (ANOVA), teniendo en cuenta la aparición de interacción entre la dosis aplicada y el tiempo post-inoculación, por lo cual se realizan particiones según el tiempo transcurrido desde la aplicación del veneno. Para aquellas variables en las que se detectaron diferencias, las medias se compararon mediante la prueba de Tukey. Para todas las inferencias se estableció un riesgo alfa del $5 \%$.

\section{RESULTADOS}

Cuadro clínico. Todos los animales sometidos al test de Coggins resultaron negativos y durante toda la experiencia se mantuvieron con coprología cuantitativa menor de 100 huevos/g. La inmunización de los equinos con veneno de $B$. alternatus causó reacciones orgánicas que se manifestaron a nivel local, además de modificaciones de los valores del hemograma, de la coagulación de la sangre y de los tenores de anticuerpos. Los signos clínicos más relevantes se iniciaron a pocos minutos de la aplicación de la vacuna, siendo bien evidentes a los $10 \mathrm{~min}$, con edema en el sitio de aplicación, inquietud, hipotensión leve valorada por el decaimiento, anorexia y en algunos casos adopción de la posición de decúbito. El edema se limitó a las áreas de vacunación y transcurridas 2-3 h se intensificó extendiéndose a regiones vecinas (gran parte del cuello, pecho y miembros), resolviéndose en el término aproximado de $72 \mathrm{~h}$.

La intensidad de la respuesta local se atenuó en las sucesivas vacunaciones (desde la cuarta en adelante), limitándose a una reacción intensa que duraba poco tiempo y se resolvía en menos de $24 \mathrm{~h}$. El estado de hipotensión se presentó únicamente tras la primera vacunación. Las inoculaciones provocaron molestias en el cuello dificultando la aprehensión de los alimentos sin afectar el apetito, ya que los animales comían sin dificultad al ofrecerle la pastura sin necesidad de inclinar el cuello.

La frecuencia cardíaca reveló bradicardia a los 10 min post-inoculación, registrándose valores de hasta $18 \mathrm{rpm}$, que se normalizaban luego de transcurrir la primera hora. Se verificó incremento de la frecuencia respiratoria (taquipnea de tipo costo-abdominal superficial), que alcanzó valores de hasta $55 \mathrm{cpm}$. La temperatura registró un aumento de hasta $1,5^{\circ} \mathrm{C}$ en los pacientes vacunados, regularizándose dentro de las 24 h. En uno de los animales se constató incremento de la coloración de la mucosa palpebral.

Los equinos inoculados mostraron disminución de los movimientos intestinales (borborigmos), sin presentar íleo adinámico ni manifestaciones de cólico. Es importante destacar que los signos clínicos relacionados a los aparatos circulatorio y respiratorio se mantuvieron estables a pesar del aumento de la dosis del inóculo.

Parámetros de la coagulación. Las primeras vacunas causaron incoagulabilidad sanguínea en todos los animales a partir de las $3 \mathrm{~h}$ post-inoculación, manteniéndose así durante $24 \mathrm{~h}$ para luego retornar a la normalidad. Posteriormente se verificó la normalización de los tiempos de protrombina (Figura 1) y de recalci-

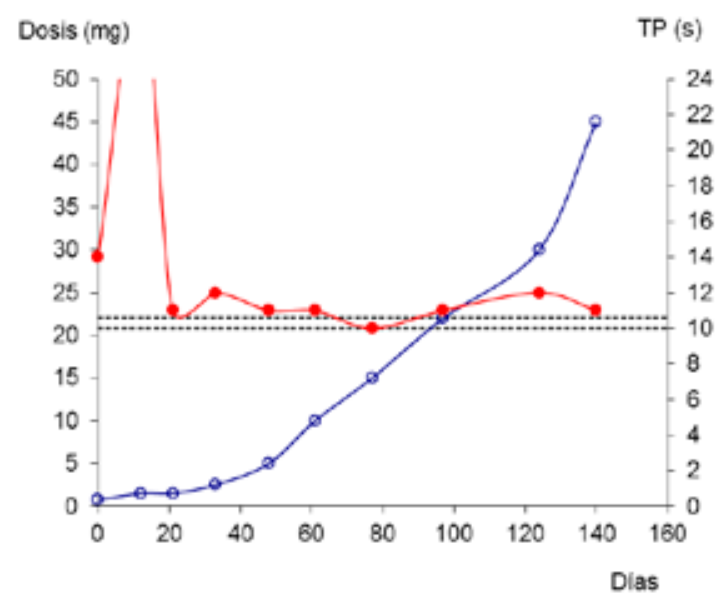

Figura 1. Variación del tiempo de protrombina (-) determinado a las $6 \mathrm{~h}$ post-inoculación. Dosis de veneno: $(\bullet)$. Las líneas punteadas indican rango de valores basales. 
ficación (Figura 2). Los niveles de fibrinógeno (Figura 3) variaron en forma concordante con los tiempos de protrombina y recalcificación. El tercer refuerzo solo afectó ligeramente los parámetros hemostáticos, comportamiento que se repitió a lo largo de todo el protocolo, indicando que los anticuerpos formados neutralizaron los componentes del veneno causantes de las alteraciones coagulativas.

Hemograma. Luego de las inmunizaciones se observaron algunas modificaciones en el hemograma de los equinos vacunados, tanto en la serie roja como blanca. El hematocrito disminuyó a partir de la primera dosis de veneno, pero luego reveló una recuperación gradual. El promedio de los valores basales del hematocrito de los tres equinos bajo ensayo fue de $33,67 \pm 2,1 \%$, valor que ante la primera dosis de veneno $(1,5 \mathrm{mg}) \mathrm{se}$ redujo a $30,2 \%$ y se acentuó ante las dosis siguientes de $2,5 \mathrm{mg}(28,0 \%)$ y $5,5 \mathrm{mg}(27,33 \%)$. A partir de la dosis de $15 \mathrm{mg}$ se advirtió una recuperación $(30,6 \%)$ que continuó con la dosis de $45 \mathrm{mg}(31,33 \%, \mathrm{p}<0,0001)$.

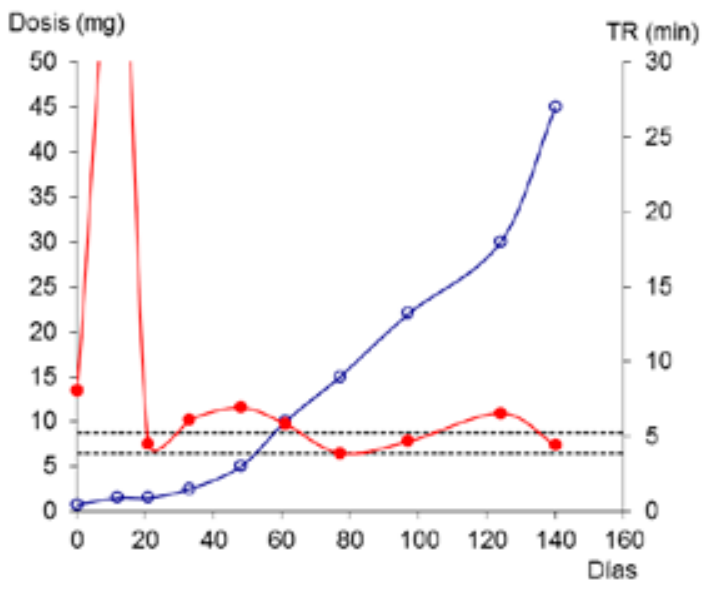

Figura 2. Variación del tiempo de recalcificación (-) determinado a las $6 \mathrm{~h}$ post-inoculación. Dosis de veneno: (-). Las líneas punteadas indican rango de valores basales.

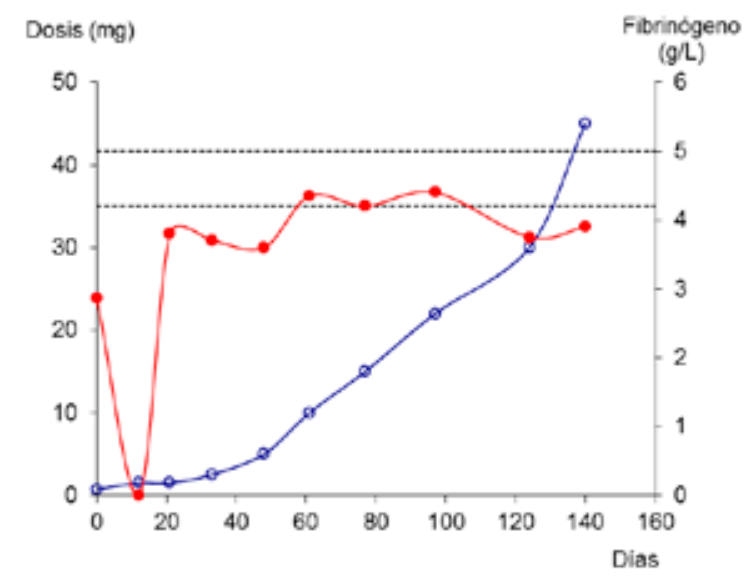

Figura 3. Variación del fibrinógeno plasmático (-) determinado a las $6 \mathrm{~h}$ post-inoculación. Dosis de veneno $(\bullet)$. Las líneas punteadas indican rango de valores basales.
Los valores de hemoglobina (Figura 4) no se redujeron luego de las dos primeras vacunas a pesar de las posibles pérdidas de sangre por hemorragia. Luego, su evolución fue coincidente con los valores del hematocrito: disminuyó ligeramente con las dosis de 2,5 y $5,5 \mathrm{mg}$ de veneno para mostrar luego una recuperación gradual. A pesar de que el protocolo de vacunación se extendió hasta el día 160, en la figura se grafican los resultados hasta el día 120 debido a que desde allí en adelante se mantuvieron sin modificaciones.

La concentración de leucocitos totales (Figura 5) reveló un pronunciado ascenso inicial después de la primera vacunación y luego, con algunas fluctuaciones, se mostró moderadamente elevada hasta el final de la inmunización. La fórmula leucocitaria exhibió un marcado predominio de neutrófilos y consecuente disminución de linfocitos, cuyos más bajos porcentajes ocurrieron luego de la segunda dosis de veneno (Figura 6). Pese a que las inoculaciones prosiguieron hasta el día 160 , en la figura se consignan las tasas obtenidas hasta el día 120 debido a que posteriormente no se registraron grandes modificaciones

Títulos de anticuerpos. Durante el plan de inoculación se presentaron variaciones plasmáticas de los títulos de anticuerpos, en función de las dosis y tiempos de vacunación (Figura 7). En las re-vacunaciones, realizadas luego de un periodo de descanso, se observó una rápida respuesta en la producción de anticuerpos. Se advirtió que el período de tres meses de descanso resulta muy extenso y conduce a una franca disminución de los títulos de anticuerpos, con pérdida de la capacidad neutralizante del suero para ciertos componentes del

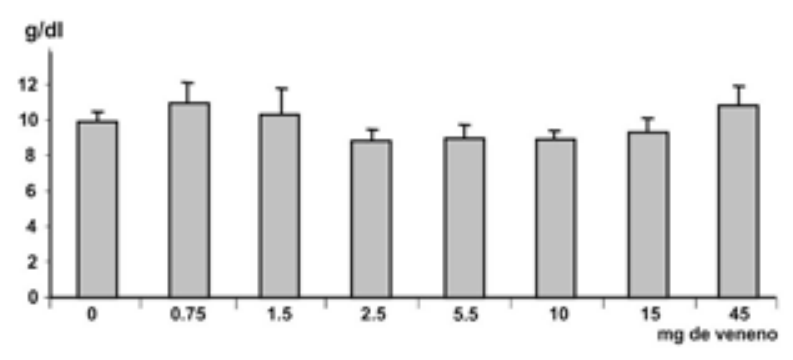

Figura 4. Variaciones de la hemoglobina (media aritmética y desvío estándar) según la dosis de veneno inoculado.

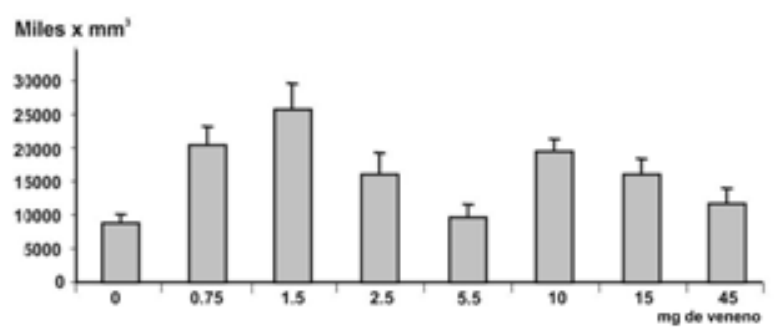

Figura 5. Concentración de leucocitos (media aritmética y desvío estándar) según la dosis de veneno inoculado. 
veneno. Sin embargo, la reposición de los anticuerpos anti-toxinas de $B$. alternatus fue rápida, tolerándose dosis de 15 y $30 \mathrm{mg}$ de veneno en el segundo periodo de inmunización.

Los ensayos de neutralización, donde el veneno preincubado con suero del equino inmunizado tornó incoagulable un plasma normal citratado, demostraron una efectiva respuesta inmunológica de los anticuerpos generados por los equinos (Tabla 1).

\section{DISCUSIÓN}

El caballo ha sido reportado como el mejor animal productor de sueros hiperinmunes por su fácil manejo y alto rendimiento de plasma ${ }^{10}$. Para la producción de inmunoglobulinas, los animales son sometidos a vacunaciones sucesivas, con dosis crecientes de veneno. Cada vacuna implica la administración de un paquete enzimático altamente nocivo que si bien no causa intoxicación severa, genera reacciones locales y sistémicas que deben ser tenidas en cuenta. En Argentina existen pocas investigaciones acerca de las alteraciones clínicas y hematológicas en animales sometidos a vacunaciones con venenos de serpientes para la producción de anticuerpos. Sin embargo son bien conocidos los daños locales y sistémicos causados en seres humanos y animales por la mordedura de serpientes como las del género Bothrops ("yararás") 4, 14, 15 .

En el presente trabajo las vacunaciones se efectuaron con un solo veneno e inicialmente con dosis bajas, por lo cual se registraron escasas manifestaciones clínicas propias de la intoxicación botrópica leve. Los animales bajo ensayo presentaron un ligero sangrado local que cesó rápida y espontáneamente. Respecto a los parámetros hemostáticos, cabría inferir que en la primera dosis la cantidad de veneno presumiblemente no haya sido suficiente para modificar el tiempo de coagulación. Sin embargo en la segunda dosis se evidenció un sensible aumento de esta prueba, para retornar a la normalidad en el término de $24 \mathrm{~h}$. El tercer refuerzo sólo afectó ligeramente los parámetros coagulativos,

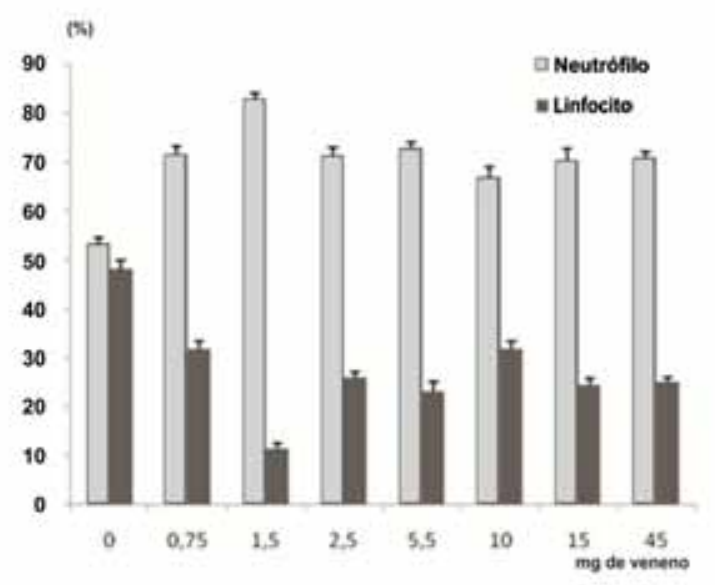

Figura 6. Porcentajes de neutrófilos y linfocitos (media aritmética y desvío estándar) según la dosis de veneno inoculado.
Tabla 1. Variaciones en la capacidad neutralizante del suero equino hiperinmune.

\begin{tabular}{lcccc}
\hline actividad & $\begin{array}{c}\text { última } \\
\text { inoculación }\end{array}$ & $\begin{array}{c}\text { final período } \\
\text { de descanso }\end{array}$ & $\begin{array}{c}\mathrm{R}: 15 \mathrm{mg} \\
\text { de veneno }\end{array}$ & $\begin{array}{c}\mathrm{R}: 30 \mathrm{mg} \\
\text { de veneno }\end{array}$ \\
\hline hemolítica & 100 & 0 & 11 & 57 \\
proteolítica & 100 & 0 & 27 & 100 \\
coagulante & 100 & 0 & 38 & 100 \\
\hline
\end{tabular}

R: reinoculación. Los números indican porcentaje de neutralización.

comportamiento que se repitió a lo largo de todo el protocolo, indicando que los anticuerpos formados fueron capaces de neutralizar los componentes del veneno que afectan la coagulación sanguínea. En consecuencia no se manifestaron coagulopatías sistémicas pese a que tanto el tiempo de recalcificación del plasma como el tiempo de protrombina, indicaron incoagulabilidad sanguínea hasta las $24 \mathrm{~h}$.

Tales resultados se correspondieron con los obtenidos en los ensayos de neutralización, donde el veneno pre-incubado con suero del equino inmunizado tornó incoagulable un plasma citratado normal, demostrando efectiva respuesta inmunológica por parte del equino, al neutralizar proteínas tipo trombina contenida en el veneno. Concomitantemente, en la segunda vacunación se verificó una brusca disminución del fibrinógeno sanguíneo, aunque las vacunaciones subsiguientes solo causaron ligero consumo de dicha proteína. Ello refuerza la certeza de la ausencia de trastornos hemostáticos en los equinos.

No obstante, utilizando bajas dosis de veneno para la producción de sueros antiofídicos polivalentes con vacunas que se elaboran con mezclas de distintos venenos, otros investigadores habrían registrado efectos más intensos ${ }^{1}$. Por tales razones se han sugerido técnicas para minimizar la acción tóxica de los venenos en

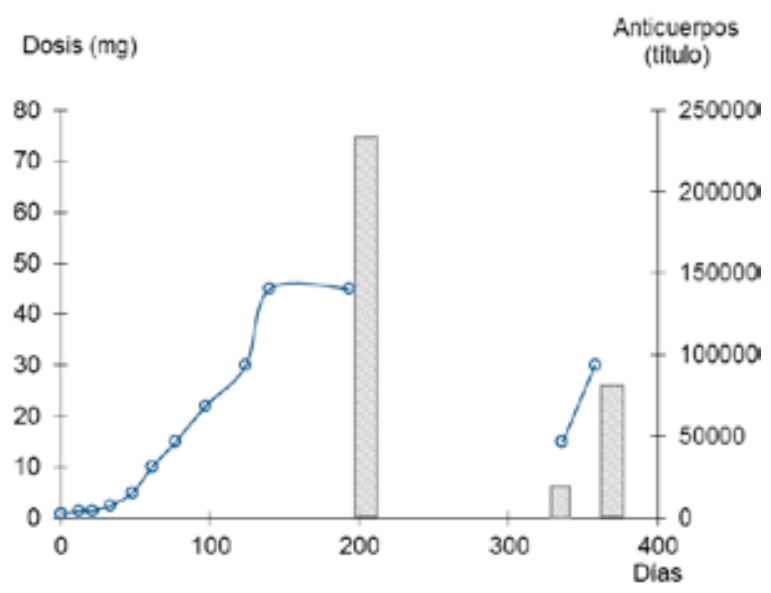

Figura 7. Tasa sérica de anticuerpos en los equinos inmunizados. La curva ( $(\bullet)$ indica las dosis de veneno y las barras señalan títulos de anticuerpos. El tiempo comprendido entre los días 250 y 300 corresponde al reposo de los animales. 
el proceso de inmunización, modificando sus propiedades químicas a través de métodos físicos; sin embargo este proceso puede causar alteraciones estructurales en las proteínas del veneno, con modificaciones de los epítopos y consecuente alteración en los anticuerpos formados contra las toxinas modificadas ${ }^{6,7}$, interfiriendo la eficiencia terapéutica de los anticuerpos en el paciente accidentado. Por tales razones, en el presente ensayo se utilizó únicamente veneno entero no modificado.

Las disminuciones del hematocrito aquí registradas luego de las primeras inoculaciones de veneno deberían atribuirse a pequeñas hemorragias indetectables a la exploración clínica. Sin embargo, la hemoglobina mantuvo inicialmente su nivel basal, quizás debido a que el dolor causado por las inoculaciones interfirió con la ingestión de agua, generando hemoconcentración. Otros investigadores detectaron importantes disminuciones de hematocrito y hemoglobina en las fases finales del protocolo de vacunación para la producción de suero polivalente, utilizando mezclas de venenos de diferentes serpientes del género Crotalus ${ }^{1}$, situación no observada en este trabajo.

Reducciones de hematocrito y hemoglobina también fueron registrados en el envenenamiento humano, posiblemente a consecuencia de hemorragias ya que en accidentes naturales la cantidad de veneno inoculado puede superar, en mucho, a la dosis utilizada como vacuna en nuestro caso ${ }^{2,11,13}$. En la presente experiencia, las vacunas sucesivas estimularon la producción de anticuerpos que impidieron efectos adversos sobre la serie roja hacia el final del protocolo de vacunación.

La leucocitosis registrada a partir de la primera vacuna en los equinos aquí estudiados se debió al aumento de neutrófilos, los cuales permanecieron elevados durante todo el proceso de inmunización. En accidente humanos es típico, como en este caso, encontrar leucocitosis con neutrofilia ${ }^{11}$, aunque en otros trabajos se hallaron incrementos simultáneos de linfocitos ${ }^{1}$.

Luego del período de descanso de 3 meses se comprobó que el suero de los caballos no presentaba capacidad neutralizante y que el título había descendido a 1:8000. No obstante, luego de la primer re-vacunación se constató una rápida elevación del título de anticuerpos, detectándose capacidad neutralizante parcial sobre las actividades proteolítica, hemolítica indirecta y coagulante, mientras que en el segundo refuerzo, el título alcanzó valores de 1:70000, con neutralización total de las actividades coagulante y proteolítica, así como capacidad neutralizante parcial de la actividad hemolítica indirecta. Estos resultados demuestran que la respuesta inmunológica de los equinos frente a las distintas toxinas del veneno es variable, dependiendo probablemente de la capacidad inmunogénica de cada antígeno, así como de su abundancia relativa en la composición del veneno total, por ello algunas antitoxinas alcanzan títulos sensiblemente mayores que otras.

En conclusión, los resultados indican que la inmunización de los equinos con el protocolo utilizado para la producción de suero antiofídico monovalente contra $B$. alternatus, induce alteraciones clínicas y cambios en ciertos parámetros del hemograma. El estudio también pone de relieve la variabilidad de la respuesta inmune en su capacidad neutralizante sobre distintos componentes del veneno, en especial las toxinas que afectan la coagulación de la sangre, ya que dosis muy bajas pueden poner en riesgo la salud de un animal de más de $400 \mathrm{~kg}$ de peso. Asimismo, se constató correlación entre los niveles de glóbulos blancos circulantes y la producción de inmunoglobulinas. Se destaca que un trimestre es un periodo de descanso extenso, que conduce a una franca disminución sérica del título de anticuerpos y pérdida de la capacidad neutralizante de la toxicidad del veneno, aunque el equino es capaz de desplegar una veloz reposición de los anticuerpos antitoxinas de B. alternatus y tolerar altas dosis de veneno en el segundo período de inmunización.

Agradecimientos. A la Dra M.E. García Denegri por su colaboración en la elaboración de algunas de las vacunas. Al MV J. Picot por su participación en los análisis estadísticos. A la Lic L. Rey y al serpentario del Zoológico de la Ciudad de Corrientes por aportar el veneno utilizado en el trabajo.

\section{REFERENCIAS}

1. Angulo Y, Estada R, Gutiérrez JM. 1997. Clinical and laboratory alterations in horses during immunization with snake venoms for the production of polyvalent (Crotalinae) antivenom. Toxicon 35: 81-90.

2. Bolaños R. 1982. Las serpientes venenosas de centroamérica y el problema del ofidismo. Rev Cost Cien Med 3: 165184.

3. Chippaux JP, Goyffon M. 1998. Venoms, antivenoms and immunotherapy. Toxicon 36: 823-846.

4. Esteso SC. 2005. Ofidismo en la República Argentina, Ed. Arpon, Córdoba (Argentina), $176 \mathrm{p}$.

5. Gutiérrez JM, Chávez F, Elizondo J, Ávila C, Cerdas L. 1988. Production of monovalent anti-Bothrops asper antivenom: development of immune response in horses and neutralizing ability. Rev Biol Trop 36: 511-517.

6. Hati RN, Mandal M, Hati AK. 1990. Active immunization of rabbit with gamma irradiated Russell's viper venom toxoid. Toxicon 28: 895-902.

7. Higashi HG, Guidolin R, Nishikawa AK, Yamaguchi IK, Lima ML, Diaz W. 1989. Venenos botrópicos pretratados com inibidores ativos para os sitios enzimáticos de proteases e com substancias quelantes preservam seu poder inmunogénico. Mem Inst Butatan 51: 107-115.

8. Organización Mundial de la Salud. 1969. Normas para los sueros inmunes de origen animal. Serie de Informes Técnicos No 413, Ed. OMS, Ginebra, p. 49-64.

9. Organización Mundial de la Salud. 1980. WHO Guidelines for the production control and regulation snake antivenoms immunoglobulins. http://who.int/bloodproduc ts/ snake_antivenoms/snakeantivenomguideline.pdf. 
10. Organización Panamericana de la Salud. 1977. Producción y pruebas de control en la preparación de antisueros diftérico, tetánico, botulínico, antivenenosos y gangrena gaseosa. Publ. OPS, Washington, p. 104-141.

11. Otero R, Tabón GS, Gómez LF, Osorio R, Valderrama R, Hoyos D, Urreta JE, Molina S, Arboleda JJ. 1992. Accidente ofídico en Antioquia y Chocó. Aspectos clínicos y epidemiológicos. Acta Méd Colomb 17: 229-249.

12. Reid HA, Theakston RD. 1984. Les morsures de serpent. Bull Org Mond Santé 62: 27-38.

13. Russell FE. 1980. Snake venom poisoning, Ed. J.B. Lippincott, Philadelphia, $562 \mathrm{p}$.

14. Ruiz RM, Ulón SN, Sario HM. 2004. Epidemiología del accidente ofídico en la Provincia de Corrientes. Sesión Comunic Cientif Tecnol UNNE (Argentina), V-029.
15. Sanchez EF, Freitas TV, Ferreira DL, Velarde DT, Diniz MR, Cordeiro MN, Agostini G, Diniz CR. 1992. Biological activities of venoms from South American snakes. Toxicon 30: 95-103.

16. Theakston RD, Warrell DA, Griffiths E. 2003. Report of a WHO workshop on the standardization and control of antivenoms. Toxicon 41: 541-557.

17. Vieira DF, Watanabe L, Santana CD, Marcussi S, Sampaio SV, Soares AM, Arni RK. 2004. Purification and characterization of jararassin-I, a thrombin-like enzyme from Bothrops jararaca snake venom. Acta Biochim Biophys 36: 798-802.

18. Wang WJ, Huang TF. 2002. Purification and characterization of a novel metalloproteinase, acurhagin, from $\mathrm{Ag}$ kistrodon acutus venom. Thromb Haemost 87: 641-650.

\section{SJR $\begin{aligned} & \text { SClmago } \\ & \text { Journal \& Country } \\ & \text { Rank }\end{aligned}$}

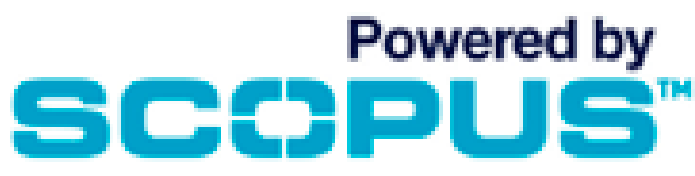

\section{Índice de impacto de Revista Veterinaria}

Noticias de Scimago Research Group (Scimago Journals \& Country Ranks, Scopus-Elsevier) comunican que la publicación de nuestra casa, Revista Veterinaria, continúa registrando índice de impacto. El índice SJR mide la influencia científica (impacto) del artículo de una revista, expresando cuán importante es el "artículo promedio" de la publicación en la discusión científica global (sistema Thomson Reuters).

Para nuestra revista, tal indicador había sido de 0,03 en 2008 y continuó en 2009, 2010 y 2011 exhibiendo ahora un nivel promedio de 0,05 (media de 3 últimos años). Asimismo, surge para nuestra publicación un sostenido descenso del indicador que relaciona "citas versus autocitas", demostrando que los autores de los artículos están abandonando la práctica de citar sus propias publicaciones anteriores.

Por último, se advierte que según este portal, nuestra "Revista Veterinaria" continúa siendo la única publicación de esta rama de la ciencia que posee índice de impacto en Argentina. Para el resto del cono sur tal distinción recae en Brasil (siete revistas), Chile (una revista), Colombia (una revista) y Venezuela (una revista). No registran índice de impacto las revistas de veterinaria de Bolivia, Paraguay, Uruguay, Perú y Ecuador. 